\section{A split-face of dermaroller and intradermal injection with the autologous platelet rich fibrin lysate in the treatment of exogenous ocronosis: A case series}

\author{
Moerbono Mochtar, Sri Esa Ilona, \\ Dendi Zulfikar, Ammarilis Murastami, \\ Suci Widhiati \\ Dermatovenereology Department, \\ Faculty of Medicine, Sebelas Maret \\ University/Dr. Moewardi General \\ Hospital, Surakarta, Indonesia
}

\begin{abstract}
Exogenous ochronosis (EO) is a rare, cosmetically disfiguring condition, resulting from the long term use of topical hydroquinone in treatment of melasma. The studies about it are small and many of the treatments have mixed result. Autologous human platelet rich fibrin (PRF-L) is contains platelet that are purpose to release numerous growth factor that valuable in numerous dermatologic application.Platelet rich fibrin lysate used for EO has not been reported. We presented three cases with EO treated with split-face of the PRF-L applied right before dermaroller on right face and intradermal injection on the left for 8 weeks. The treatment re-apply every 2 weeks. The improvement was measuring by 10-point grading scale and dermoscopic examination, including five-point grading scale to assessment of patient satisfaction. All of three patients demonstrated significant improvementand very satisfied in 4th week of treatment. This result suggests that PRF-L can be used as of one modality for EO treatment.
\end{abstract}

\section{Introduction}

Exogenous ochronosis (EO) is a cutaneous disorder, manifests as gray-brown or blue-black macules, commonly resulting as a complication of long-term application of skin-lightening creams containing hydroquinone, but may also occur due to topical application of phenol, resorcinol or use of systemic antimalarials such as quinine. ${ }^{1}$ Until now the exact incidence of EO is not known. The worldwide incidence has been assumed to be low. It is widely found in dark-skinned people of Africa. ${ }^{2}$ The incidence in Asian is low, but cases are increasingly reported from India, China, Thailand and Singapore. ${ }^{1}$ Tan reported 15 new cases from Singapore occurred in ethnic Chinese Asians in 5 year duration. ${ }^{3}$

Early diagnosis is necessary to discontinue of the causative agent and prevent worse hyperpigmentation. ${ }^{2}$ It can distinguish from melasma on histophatologic that characterized by yellow-brown, banana shape pigment fibers in the dermis. ${ }^{2}$ Dermoscopy as a noninvasive diagnostic tools has a unique and point towards a clue for EO diagnosis and also can differentiated from melasma. ${ }^{2,4}$ The treatment for EO remains difficult, a cosmetically disfiguring and troubling disorder with disappointing treatment options are present. ${ }^{5}$

Platelet-rich fibrin as a second generation of platelet concentrates. In 2001, Choukroun et al., in France was first developed it. ${ }^{6}$ Unlike the first generation of platelet-rich products, such as platelet-rich plasma (PRP), PRF has more simplified preparation without biochemical blood handling. Nevertheless, PRF remain rich material of growth factor that contained in alpha granules. Alpha granules contains more than 30 bioactive substance, among others are: platelet-derived growth factor (PDGF), transforming growth factor beta (TGF- $\beta 1$ and 2), epithelial growth factor (EGF), and mithotic growth factor (MGF) including vascular endothelial growth factor, plateletderived angiogenesis factor and fibrinogen. These growth factor play a role in blood vessel formation, collagen synthesis and extracellular matrix components including hyaluronic acid. Transforming growth factor beta 1 have been known can inhibite and degradation of tyrosinase enzyme, and inhibite maturation of melanosom in melasma. From the mechanism mention above, PRF-L may be useful for treatment of EO. Dermaroller and intradermal injection are two procedure that can help penetration of PRF-L into the skin. ${ }^{7}$ The aim of this study are to determine the efficacy of the PRF-L in EO and to compare the efficacy of dermaroller and intradermal injection in EO with split-face technique. The secondary objective is to evaluate the effect of the PRF-L on the overall facial appearance of the patients and their respective satisfaction with their improvements or lack thereof.

\section{Case Report}

Three healty javanis women, aged 4550 years old, presented of history of melasma in their face variing since 2,5 , and 6 years ago, mentioned progressive onset of dark facial lesions following long term use of skin lightening. All patients did not know the contain of the cream that they have been used. They got it from dermatologist and
Correspondence: Dendi Zulfikar, Dermatovenereology Department, Faculty of Medicine, Sebelas Maret University/Dr. Moewardi General Hospital, Jl. Kol. Sutarto, no.132 Jebres Surakarta, Indonesia.

Tel.: 081236190103.

E-mail: dendyzulfikar@gmail.com

Key words: Exogenous ocronosis, Melasma, Platelet rich fibrin lysate.

Contributions: The authors contributed equally.

Conflict of interests: Dr. Zulfikar has nothing to disclose.

Received for publication: 1 February 2019. Accepted for publication: 25 February 2019.

This work is licensed under a Creative Commons Attribution-NonCommercial 4.0 International License (CC BY-NC 4.0).

CC Copyright M. Mochtar et al., 2019

Licensee PAGEPress, Italy

Dermatology Reports 2019; 11(s1):8090

doi:10.4081/dr.2019.8090

then continued using the product without reconsultation. They denied any other symptoms, similar family history, history of use oral medication and comorbidities. All the patients are not pregnant and on breasfeeding term, no history of using hormonal contraceptive, anti-aging or skin lightening product over the previous four week, they also did not have received any cosmetic clinical procedure in the last 2 months, and there are no pre-existing skin disease on the procedure area. Physical examination revealed marked pacth hyperpigmentation, eritema, depigmented macule and telangiectasia on their face. We diagnosed them with exogenous ocronosis with simple skin stretching, Wood's lamp and dermoscopic examination (Figure 1a).

After signed written informed-concent, the patients were treated with autologous PRF-L. It taken form the peripheral blood, immediately in 2 minutes, the sample is inserted into a $10 \mathrm{~mL}$ sterile glass tube without anticoagulation, then centrifuged at $2700 \mathrm{rpm}$ or about $400 \mathrm{G}$ for 12 minutes. Then waited for 5 minutes for completely coagulated. The PRF gel is located between the plasma at the top and erythrocytes at the bottom. Then, the gel pulled out from the tube using sterile tweezers and cut using sterile scissors on the PRF's gel border with erythrocytes. The gel is immediately inserted into a new sterile glass tube and then incubated for 24 hours in $4{ }^{\circ} \mathrm{C}$. The result is supernatant that called PRF-L. Before treatment procedure, the face cleansed 
using face cleanser and applied topical anestesia for approximately 1 hour. Then the PRF-L applied right before dermaroller (1 $\mathrm{mm})$ on right face and intradermal injection with disposible $1 \mathrm{ml}$ syringe on the left face. All patients given sunblock SPF 30 applied in the morning after procedure.

All patient were required to be available for longitudinal evaluation at least for 2 months. Digital photography was taken at baseline, and every 2 weeks of follow up. Two physicians graded improvement in the apperance of EO in a blinded mainner using 10-point scale (each point equal to a $10 \%$ improvement) and then comparing the post treatment result and the baseline. Patients were asked to rate their improvement base on their own perception without any photographs. Patients also rate their satisfaction with the visual improvement or lack thereof, the obtained on either side of their face at 4 weeks and 8 weeks using a five-point scale $(0=$ not satisfied, $1=$ mildly satisfied, 2 = moderately satisfied, 3 $=$ very satisfactied and $4=$ extremely satisfied). We still going on the treatment periode for 1 month. But, in $4^{\text {th }}$ week of follow up there are improvement seen from dermoscopic examination (Figure 1b), on their appearance score (Table 1) and also on the patient satisfaction rate (Figure 2). Figure 3 shows the improvement in physical examination in one of these three patients.

\section{Discussion}

Exogenous ocronosis is an acquired condition confined to the skin characterized by gray-brown or blue-black discoloration macule, usually with hypercromic, pinpoint, caviar-like papules in photoexposed regions over osseous surfaces that is the zigomatic regions in a symmetrical pattern. ${ }^{1}$ Dogliotti and Leibowith classified EO for 3 staged of severity. Stage I is erythema and mild pigmentation of the face and neck; stage II is a progression to hyperpigmentation, black colloid milia, and atrophy with the appearance of 'caviar-like' papules; and stage III includes papulonodules with or without surrounding inflammation. ${ }^{2,5}$

The pathogenesis of EO is unclear. There are various theory explain it, and still in debate that ocronotic pigment is produced from the breakdown of abnormal collagen fibers. The most widely accepted theory is that of Penneys who postulated that hidroqinone of inhibits the homogentisic acid oxidase enzyme. This inhibition leads, like in endogenous ochronosis, to the accumulation of homogentisic acid that poly- merizes to form ochronotic pigment and being deposited in the papillary dermis. ${ }^{4,5}$ It also can occured as a result of contact with other chemical product, such as resorcin, phenol, mercury, picric acid, and antimalarial drugs, but the mechanisms also unknown. $^{5}$

Various other factors predispose EO such as unprotected prolonged sun-exposure, prolonged use of skin-lightening agents mainly containing hydroquinone, presence of a number of viable melanocytes, outdoor occupation, application of hydroquinone over a larger area or whole body and/or applying hydroquinone in large quantity. ${ }^{1}$

The gold standart for diagnosis of EO is biopsy, EO's lesion present as pigmentary incontinence, solar elastosis, yellow-brown curvilinear 'banana-shaped' ochronotic fiber in the papillary dermis and eventual collagen degeneration. Occasionally, colloid milium and granulomas may be shown. ${ }^{2,4,5}$ But, nowdays dermoscopic examination for EO is widely used after it first repoted in 2008. ${ }^{2}$ Dermoscopy can also distinguish EO from melasma. From dermoscopic examination, EO shown bluegrey, granular and annular structures around follicles, some follicular openings, white dots correspond to confetti-like depigmentation. ${ }^{4,8}$ Moreover, Dermoscope reported used to assess the efficacy of PRP on face and neck revitalization, in skin rejuvenation and in scar reduction. ${ }^{9}$

Exogenous ocronosis's treatment is not easy, therefore prevention is extremely important. The use of lower hidroquinone concentrations, sun protection, early diagnosis of irritation and suspension of treatment in case there is no clinical improvement within six months are measures that should be for EO prevention. ${ }^{5}$ Hidroquinone using needs regular medical follow-up in every 3 months for Fitzpatrick type V-VI patients and in every 6 months for lighter skin types. ${ }^{3,10}$ Avoiding the causative agent of the disease is the first step to be taken and has been proven to be beneficial, although the results are seen only a few years after interruption of the treatment. ${ }^{5}$

Various treatment has been used for EO such as tricloroacetic acid aplication, retinoic acid, low potency corticosteroid with photoprotection, cryotherapy, dermabration, $\mathrm{CO}_{2}$ laser, glycolic acid peeling and $\mathrm{Q}$ swithched laser. ${ }^{5,11}$ However, the results are vary, from inefficient to satisfactory, and this condition continues to be difficult case to treat. ${ }^{5}$

Aplication of PRP in hyperpigmented lesions was obtained from several case reports that showed satisfactory results: Autologous PRP injections used for periorbital hyperpigmentation lesions, ${ }^{12}$ intradermal injection of PRP for treatment of melasma, ${ }^{13}$ and intradermal injections of autologous PRP as an adjunctive to laser therapy in melasma. ${ }^{7}$ We used PRF-L to all patients, couse the main approach of PRF concept was to keep the methodology convenient

Table 1. The Improvement in Appearent of Melasma using 10-point grading scale.

\begin{tabular}{|c|c|c|c|c|}
\hline \multirow[t]{2}{*}{ Patient } & \multicolumn{2}{|c|}{ Blinded patient } & \multicolumn{2}{|c|}{2 physicians } \\
\hline & Right cheek & Left cheek & Right cheek & Left cheek \\
\hline Mrs. E & 8 & 8 & 7 & 8 \\
\hline Mrs. M & 6 & 6 & 7 & 6 \\
\hline Mrs. S & 6 & 6 & 6 & 7 \\
\hline Mean & 6,9 & 6,7 & 6,7 & 7 \\
\hline
\end{tabular}

patient improvement satisfaction

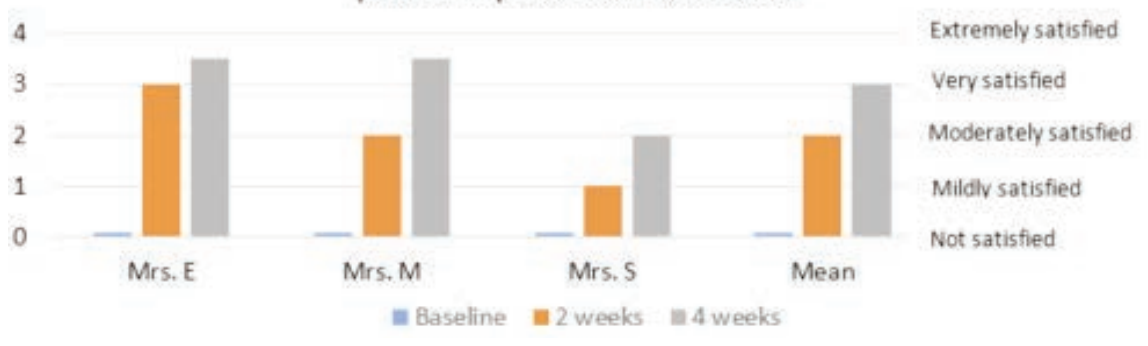

Figure 1. Blinded patients rated their satisfaction with improvement in their facial after 2 and 4 weeks of treatment. Data shown that all patients very satisfied with the improvement of the treatment. 
and applicable for clinical use. This fibrin scaffold, which does not possess any cytotoxic potential is obtained autologus from the patient's own blood after one centrifugation step. The factors previously used in the preparation of blood-based scaffolds, like anticoagulants or bovine serum that used in PRP, were excluded from this preparation procedure. It allowed the risk of trans-contamination to be minimized. The three-dimensional fibrin network is capable of mimicking the extracellular matrix in terms of its structure, which creates the environment for cells to function optimally. ${ }^{14}$ Wirohadidjojo et al, concluded that PRF-L is a good candidate
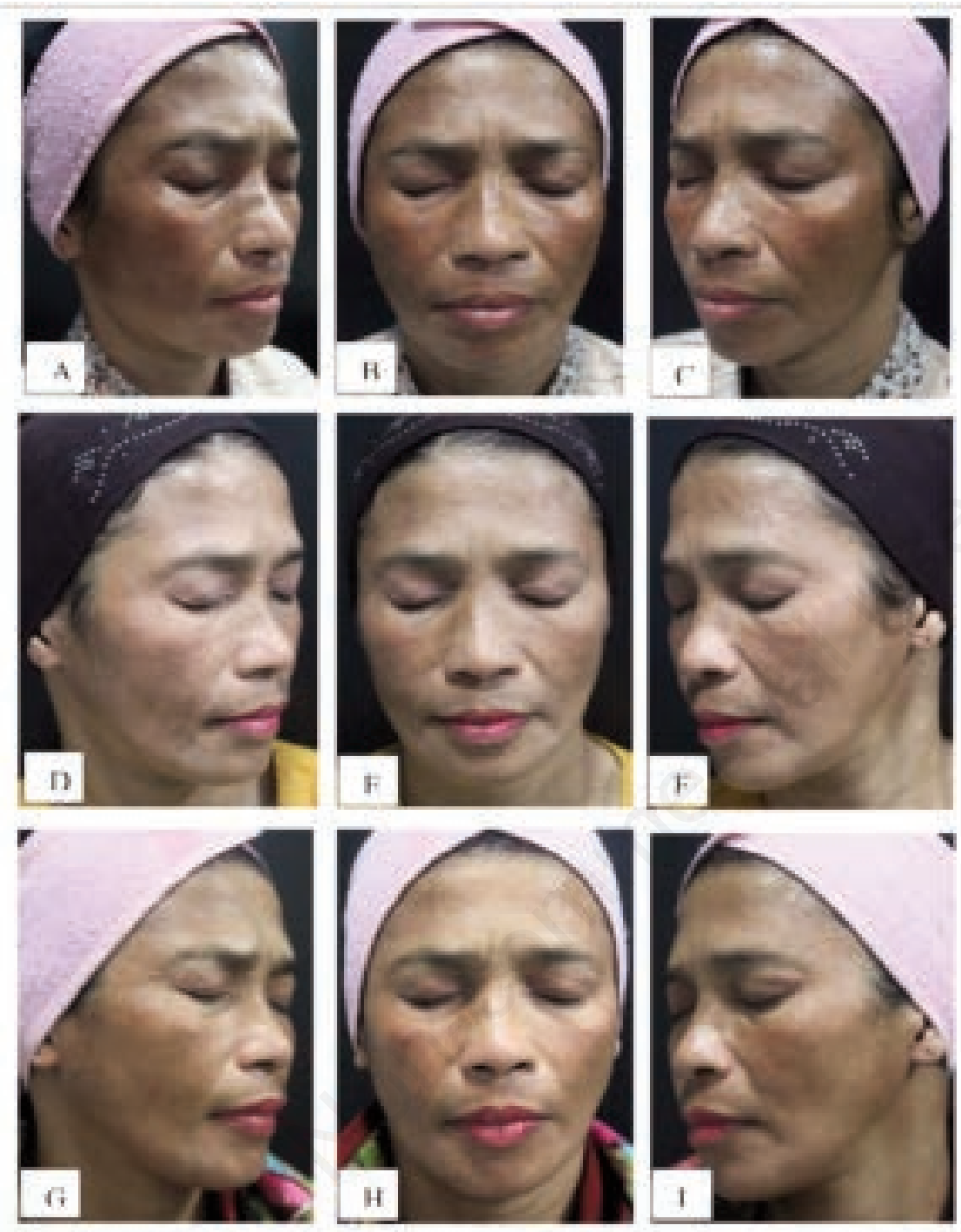

Figure 2. (A-I). Photographs of Mrs. E. (A-C) at baseline, (D-F) at 2 weeks treatment, and (G-I) at 4 weeks treatment.
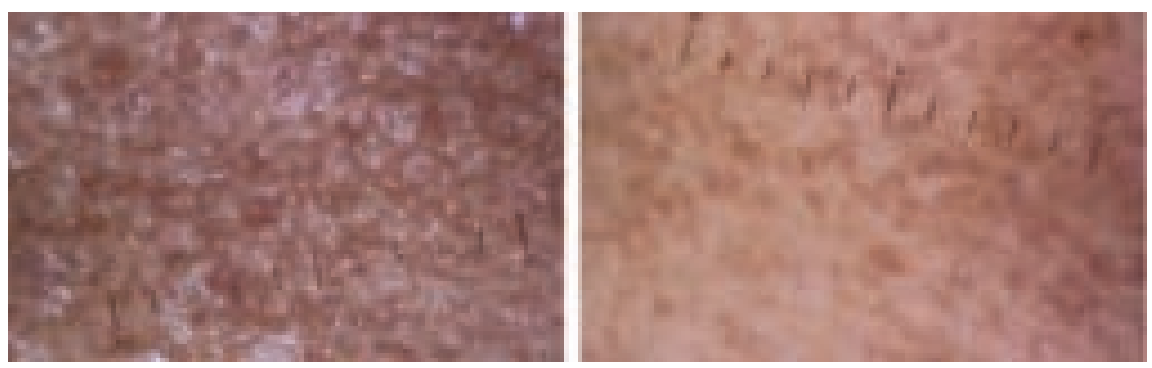

Figure 3 (A and B). Dermoscopic examination Mrs E. (A). at baseline (B). at 4 weeks treatment.

material for treating UVA-induced skin photoaging that showed significant decreased in proliferation, migration, and collagen deposition rate. ${ }^{15}$

\section{Conclusions}

A case series of split-face of dermaroller and intradermal injection with the autologous platelet rich fibrin lysate in the treatment of exogenous ocronosis were reported. The treatment procedure are lowcost and easy to apply. All patient show significant improvement and with high satisfaction at 4 weeks of treatment.

\section{References}

1. Bhattar PA, Zawar VP, Godse KV, Patil SP, Nadkarni NJ, Gautam MM. Exogenous Ochronosis. Indian Journal of Dermatology. 2015;60(6):537-543.

2. Simmons BJ, Nouri K, Griffith RD, Bray FN, Falto-Aizpurua LA. Exogenous ochronosis: A comprehensive review of the diagnosis, epidemiology, causes, and treatments. Am J Clin Dermatol. 2015:1-8.

3. Tan SK. Exogenous ochronosis in ethnic Chinese Asians: A clinicopathological study, diagnosis and treatment. J Eur Acad Dermatol Venereol. 2011;25:84280.

4. Mishra SN, Dhurat RS, Deshpande DJ, Nayak CS. Diagnostic utility of dermatoscopy in hydroquinone-induced exogenous ochronosis. Int J Dermatol. 2012:1-5.

5. Martins VMR, Portela NdC, Gonçalves LMS, Sousa ARDd, Tigre CAF, Filho RJdLC. Exogenous ochronosis: case report and literature review. An Bras Dermatol. 2012;87(4):633-6.

6. Dohan DM, Choukroun J, Diss A, Dohan SL, Dohan AJJ, Mouhyi J, dkk. Platelet-rich fibrin (PRF): A secondgeneration platelet concentrate. Part I: Technological concepts and evolution. Oral Surg Oral Med Oral Pathol Oral Radiol Endod. 2006;101:E37-44.

7. Yew CH, Ramasamy TS, Amini F. Response to intradermal autologous platelet rich plasma injection in refractory dermal melasma: Report of two cases. JUMMEC. 2015;18(2):1-6.

8. Romero SAR, Mariano AVdO, Francesconi VA, Pereira PMR, Francesconi F. Use of dermoscopy for diagnosis of exogenous ochronosis. An Bras Dermatol. 2011;86(4Supl1):S31-4.

9. Hersant B, Abbou R, SidAhmed-Mezi M, Meningaud JP. Assessment tools for facial rejuvenation treatment: A review. 
Aesth Plast Surg. 2016:1-10.

10. Shankar K, Godse K, Aurangabadkar S, Lahiri K, Mysore V, Ganjoo A, dkk. Evidence-based treatment for melasma: Expert opinion and a review. Dermatol Ther (Heidelb). 2014:1-22.

11. Kanechorn-Na-Ayuthaya Niumphradit N, Aunhachoke K Nakakes A, Sittiwangkul R, Srisuttiyakorn C. Effect of combination of $1064 \mathrm{~nm}$ Q-switched Nd:YAG and fractional carbon dioxide lasers for treating exogenous ochronosis. J Cosmet Laser Ther. 2013;15:42-45.

12. Al-Shami SH. Treatment of periorbital hyperpigmentation using platelet-rich plasma injections. Am J Dermatol Venereol. 2014;3(5):87-94.

P, 13. Cayirli M, Caliskan E, Acikgoz G, Erbil

, AH, Erturk G. Regression of melasma

with platelet-rich plasma treatment. Ann Dermatol. 2014;26(3):401-2.

14. Ghanaati S, Booms P, Orlowska A, Kubesch A, Lorenz J, Rutkowski J, dkk.
Advanced Platelet-Rich Fibrin (A-PRF) - A new concept for cell-based tissue engineering by means of inflammatory cells. Journal of Oral Implantology. 2014:1-34.

15. Wirohadidjojo YW, Budiyanto A, Soebono H. Platelet-rich fibrin lysate can ameliorate dysfunction of chronically UVA-irradiated human dermal fibroblasts. Yonsei Med J. 2016;57(5):1282-85. 